\title{
Risky driving behaviour in Abu Dhabi, United Arab Emirates: a cross-sectional, survey-based study
}

\author{
Latifa Mohammad Baynouna AlKetbi ${ }^{1^{*}}$ D, Michal Grivna ${ }^{2}$ and Saeed Al Dhaheri ${ }^{3}$
}

\begin{abstract}
Background: Traffic collision fatality rates per mile travelled have declined in Abu Dhabi similar to many developed countries. Nevertheless, the rate is still significantly higher than the average of countries with similar GDP and sociodemographic indicators. The literature on the subject in the UAE is limited especially in the area of studying drivers behaviour. This study aims to find determinants of risky driving behaviours that precipitate having a road traffic collision (RTC) in the United Arab Emirates (UAE).
\end{abstract}

Methods: A cross-sectional, survey-based study was employed. Participants were 327 active drivers who were attending Abu Dhabi Ambulatory Health Care Services clinics. They were provided with a questionnaire consisting of demography, lifestyle history, medical history, driving history, and an RTC history. They were also given a driving behaviour questionnaire, a distracted driving survey, depression screening and anxiety screening.

Results: Novice drivers (less than 25 years old) were $42 \%$ of the sample and $79 \%$ were less than 35 years. Those who reported a history of an RTC constituted $39.8 \%$ of the sample; nearly half (47.1\%) did not wear a seatbelt during the collision. High scores in the driving behaviour questionnaire and high distraction scores were evident in the sample. Most distraction-prone individuals were young (90.5\% were less than 36 years old). High scores in the driving behaviour questionnaire were also associated with high distraction scores $(p<0.001)$. Respondents with high depression risk were more likely to be involved in the RTC. With each one-point increase in the driver's distraction score, the likelihood of a car crash being reported increased by $4.9 \%$.

Conclusion: Drivers in the UAE engage in risky behaviours and they are highly distracted. Some behaviours that contribute to severe and even fatal injuries in RTCs include failing to wear a seatbelt and being distracted. Younger people were more likely distracted, while older drivers were more likely to have higher depression scores.

Depression is suggested as a determinant factor in risky driving. These findings are informative to other countries of similar socioeconomic status to the UAE and to researchers in this field in general.

Keywords: Road traffic collision, driver's behaviour, Distracted driving, Depression

\footnotetext{
* Correspondence: latifa.mohammad@gmail.com

${ }^{1}$ Ambulatory Healthcare Services. Abu Dhabi Healthcare Services, 81815 Al

Ain, United Arab Emirates

Full list of author information is available at the end of the article
}

(c) The Author(s). 2020 Open Access This article is licensed under a Creative Commons Attribution 4.0 International License, which permits use, sharing, adaptation, distribution and reproduction in any medium or format, as long as you give appropriate credit to the original author(s) and the source, provide a link to the Creative Commons licence, and indicate if changes were made. The images or other third party material in this article are included in the article's Creative Commons licence, unless indicated otherwise in a credit line to the material. If material is not included in the article's Creative Commons licence and your intended use is not permitted by statutory regulation or exceeds the permitted use, you will need to obtain permission directly from the copyright holder. To view a copy of this licence, visit http://creativecommons.org/licenses/by/4.0/ The Creative Commons Public Domain Dedication waiver (http://creativecommons.org/publicdomain/zero/1.0/) applies to the data made available in this article, unless otherwise stated in a credit line to the data. 


\section{Background}

Among all causes of mortality, Road Traffic Collisions (RTC) are the most preventable deaths worldwide. According to the World Health Organization, 3000 people die on the world's roads every day and several million are injured or disabled each year [1]. In addition, road collisions cost about $\$ 600$ billion to governments in different economies, a figure that is equivalent to the combined GDP of almost all the developing countries in the world [1]. The U.S. Department of Transportation's most recent estimate of the annual economic cost of crashes was $\$ 242$ billion [2]. Fatality rates per population and per mile travelled have declined by half in developed countries since 1975, and the fatality rate per 100 million miles travelled declined from 20.6 in 1975 to 11.4 in 2017 [3].

The UAE compared with industrialized countries, is high in terms of per capita income and has strict laws against alcohol use, strict safety vehicle licensing and high quality of roads [4] and similarly, RTC fatality rate has fallen as well. Nevertheless, the fatality rate is still significantly higher than in countries with similar GBD and socio-demographic indicators [5]. In addition death rate in Abu Dhabi is decreasing and it is lower than that of many developed countries, 18.1 per 100,000 in 2013, still Road Traffic Collision (RTC) is the second leading cause of death. The UAE has a young population with more than one-quarter of its population being younger than 25 years old [6]. The leading cause of death in this age group is road injuries [5]. Therefore, prevention and mitigation of RTCs for younger age groups is especially worthwhile since the youth are in high risk of injury because they are not restrained and have more risky driving practices, driving with no license, drug/alcohol use and distractive driving $[7,8]$.

Road traffic collisions have not been a research priority in the UAE and in the region despite of the rising awareness of its importance $[9,10]$. Therefore, confidence relating to the effectiveness of suggested interventions is uncertain [11]. It is acknowledged that strategies focused on engineering and technological advancements play a role in the prevention and mitigation of RTCs through its effect on drivers' behaviour. However, direct exploration of human factors in RTCs and targeting the prevention of death and injury by tailored human behavioural interventions and improving judgement is probably of paramount importance.

Driver's behaviour was targeted in assessment and in interventions because driving skills and bad choices are likely to increase RTC occurrences and result in higher fatality outcomes [11-13]. Although it is known from a study from the UAE that only $2 \%$ of vehicle passengers used seatbelts and 13\% of motorcyclists wore a helmet, [8] there is a need to study determinants of RTCs and risk taking by the drivers. Many assessment tools exist to screen drivers in order to identify risky drivers. Examples of these tools are the Manchester Driver Behaviour Questionnaire (DBQ) [13] and the Behaviour of Young Novice Drivers Scale (BYNDS) [14].

Implementing interventions in some countries indicated a successful reduction of RTCs [15]. In the US raising the age of licensing eliminated most crashes at age 16 and in Saudi Arabia the introduction of laws on speed restrictions and restrains use have also resulted in positive outcomes $[15,16]$. Nevertheless, researchers have suggested that road safety interventions are lacking and that there are shortcomings in the assessments of those performed [16].

This study aimed to identify risky drivers in Abu Dhabi through assessing possible determinants, including driving behaviour using combined validated tools. Although some of these factors maybe studies before but this study aims to study all these factors interaction with deeper inquiry using multiple validated tools. Such results are valuable for targeted intervention design for the Abu Dhabi drivers and could inform other countries as Abu Dhabi have high prevalence of RTC and its population have representation from different countries in the world.

\section{Method \\ Study design}

This was a cross-sectional study using self-administered questionnaire. Three hundred and twenty-seven (327) currently licensed drivers participated in the study. Sample size calculation required 317 for a confidence level of $95 \%$ and confidence interval of $5.5 \%$. All 18 years or older UAE national participants were and included. They were attending 22 Abu Dhabi government Ambulatory Healthcare (AHS) centres. Fifty questionnaires were given to each of these clinics for distribution to healthy participants attending preventive clinics for premarital university fitness and annual preventive screening. Therefore, the area where the questionnaire was distributed had a greater representation of young participants, which served the purpose of the study because they were the main targets of the research.

\section{Measures and instruments}

Participants reported their demographic data, including: age, gender, occupation, income, education, academic attainment, and living alone or with family. Information on duration of driving history, car type and RTC history was also collected. Additional sections were derived from the below validated surveys. Permissions were obtained to use them from their developers.

a. Driving behaviour assessment: A questionnaire was developed by combining questions from the Manchester Driver Behaviour Questionnaire (DBQ) [10] and the Behaviour of Young Novice Drivers Scale (BYNDS) [14]. 
The resultant questionnaire was assessed by the investigators and modified. The aim was to select the most relevant factors for the UAE in a shorter version and to avoid questions that were not applicable. This section of the questionnaire included 28 questions and was translated and validated using the front and back translation method. Twenty-eight behaviours were rated on a fourpoint scale $(0=$ never, $1=$ sometimes, $2=$ most of the time, 3 =always). Participants indicated how often they had committed every behaviour in the previous year.

b. The Distracted Driving Survey (DDS): this is a validated 11-item survey which was similarly translated. Answers were reported in a scale ranging from $1=$ never to $5=$ almost always [17] .

c. Mental health assessment: the Patient Health Questionnaire (PHQ-9) and Generalized Anxiety Disorder questionnaire (GAD-7) were used and both are already available in Arabic and are used in all AHS centres as part of routine care.

a. Other lifestyle risky behaviours, including smoking, physical inactivity, and dietary habits, were recorded.

b. Metabolic parameters, including BMI, lipids, blood pressure, and glycaemic status, were filled by a nurse from the health charts.

c. History of health conditions and comorbidities were recorded.

\section{Data management and statistical analysis}

The resulting questionnaire was piloted among 20 family medicine residents for face and content validity and for any mistranslation or interpretation that required resolution. Questionnaires were then distributed by the attending nurse in the preventive clinic. Due to the busy nature of the high-intensity centres no tracking of non-respondents was performed. Consent forms and the questionnaire were distributed for self-completion and participants were assisted when needed by the experienced healthcare personnel who had been briefed about the survey.

Questionnaires were pre-coded for data entry. Data were verified and compared to eliminate key-stroke, range and consistency errors. Analysis was done using the SPSS program, Statistical Package for the Social Sciences (IBM-SPSS version 21, Chicago, Il, USA). Frequencies and cross-tabulations were used to describe the study population. Regression analysis was used to identify significant interactions and predictors of risky driving. Probabilities of less than 0.05 were considered significant.

\section{Results}

Most of the drivers surveyed were younger than 30 years old, and male drivers were driving at a younger age than the females. Novice drivers (less than 25 years old) were $42 \%$ of the sample and $79 \%$ of them were less than 35 years (See Table 1).

More than half of the participants were college graduates, and $40 \%$ had a secondary school certificate. While one-fifth were students, government employees constituted $35 \%$ of the respondents. Around one-third had an income of more than 5500\$ and another third had an income between $2750 \$$ and $5500 \$$ AED. Half of the respondents drove a four-wheel drive car and the other half owned a sedan car.

Almost $40 \%(n=87)$ of responders reported having a previous history of a RTC and nearly half of them (47.1\%) did not wear a seatbelt during their collision. Fifty out of the 87 (57.4\%) who reported an previous history of RTC were the drivers during the collision (21.6\% of the total responders). More than one in ten $(11.3 \%$ of the total respondents) reported the collision to be significant, i.e. being transferred to hospital, being admitted to hospital or having medical consequences. Thirty-nine (11.9\%) of the respondents reported that a relative had died in an RTC. Figure 1 shows the respondent's opinion about the causes of the RTC, with other drivers being blamed as the main cause, then speed as the second cause. The least reported cause, from only two respondents, was admitting to their own poor judgement.

Reasons for not using a seatbelt are shown in Fig. 2. More than half $51.2 \%(n=63)$ of subjects reported that the main reason for not wearing a seatbelt is that they forgot, 15.4\% $(n=19)$ thought that it is uncomfortable to wear, while $10.6 \%(n=13)$ of the total respondents chose not to wear a seatbelt because it wrinkles their clothes.

Table 2 shows the distribution of the four main survey parts; Drivers' Behaviour survey, Drivers' Distraction survey, PHQ-9 and D. GAD-7. Responses to the 28 questions from the Driving Behaviour Questionnaire (DBQ) are grouped by the type of the violation and Table 3 shows the responses to individual questions. The surveyed participants show prevalent risky behaviour more in ordinary violations, such as their passengers not wearing a seatbelt, speeding to catch an event, speeding when a traffic light is yellow, speeding when there is no radar or camera present, and did not wear a seatbelt in a short distance. The proportion of participants who reported never engaging in these behaviours ranged from $41.3 \%$ (not wearing a seatbelt) to $49.2 \%$ (didn't wear a seatbelt in a short distance). Risky violations that are less prevalent are drifting, driving without a license, driving under the influence of alcohol or an illicit drug (between 79.3 and $88.5 \%$ of the respondents reporting never having engaged in these behaviours). Regarding lapses and errors, around one-third (32.5\%) did misread signs, $27.3 \%$ failed to notice pedestrians crossing, and $38.5 \%$ misjudged the speed of an oncoming 
Table 1 Demographic characteristics of the study respondents

\begin{tabular}{|c|c|c|c|c|c|c|c|}
\hline & \multicolumn{6}{|c|}{ Age groups } & \multirow{2}{*}{$\begin{array}{l}\text { Percentage } \\
\text { within } \\
\text { nationality }\end{array}$} \\
\hline & $<=25$ & $26-35$ & $36-45$ & $46-55$ & $>55$ & Total & \\
\hline \multicolumn{8}{|l|}{ Nationality and Gender } \\
\hline UAE male & $43(51.8)$ & $28(33.7)$ & $10(12)$ & $2(2.4)$ & 0 & 83 & 78.3 \\
\hline UAE female & $11(47.8)$ & $4(17.4)$ & $2(8.7)$ & $5(21.7)$ & $1(4.3)$ & 23 & 21.7 \\
\hline Total & $54(50.9)$ & $32(30.2)$ & $12(11.3)$ & $7(6.6)$ & $1(0.9)$ & 106 & 100.0 \\
\hline Non-UAE male & $32(36)$ & $41(46.1)$ & $14(15.7)$ & $2(2.2)$ & 0 & 89 & 78.8 \\
\hline Non-UAE female & $5(21.7)$ & $8(34.8)$ & $9(39.1)$ & $1(4.3)$ & 0 & 23 & 20.4 \\
\hline Total & 38 (33.6) & 49 (43.4) & $23(20.4)$ & $3(2.7)$ & 0 & 113 & 100.0 \\
\hline UAE & 75 (43.6) & $69(40.1)$ & $24(14)$ & $4(2.3)$ & 0 & 172 & 78.5 \\
\hline Non-UAE & $16(34.8)$ & $12(26.1)$ & $11(23.9)$ & $6(13)$ & $1(2.2)$ & 46 & 21.0 \\
\hline Total & $92(42)$ & $81(37)$ & $35(16)$ & $10(4.6)$ & $1(0.5)$ & 219 & 100.0 \\
\hline \multicolumn{8}{|l|}{ Education } \\
\hline Elementary & $1(33.3)$ & 0 & $2(66.7)$ & 0 & 0 & 3 & 1.3 \\
\hline Secondary & $45(50)$ & $29(32.2)$ & $12(13.3)$ & $4(44)$ & 0 & 90 & 40.0 \\
\hline University or higher & $48(37.8)$ & $52(40.9)$ & $18(14.2)$ & $7(5.5)$ & $2(1.6)$ & 127 & 56.4 \\
\hline Other & 0 & $2(40)$ & $3(60)$ & 0 & 0 & 5 & 2.2 \\
\hline Total & $94(41.8)$ & $83(36.9)$ & 35 (15.6) & $11(4.9)$ & $2(0.9)$ & 225 & 100 \\
\hline \multicolumn{8}{|l|}{ Occupation } \\
\hline Student & $38(90.5)$ & $4(9.5)$ & 0 & 0 & 0 & 42 & 18.6 \\
\hline Personal business & $1(16.70$ & $3(50)$ & $1(16.7)$ & $1(16.7)$ & 0 & 6 & 2.7 \\
\hline Private sector & $11(50)$ & $10(45.5)$ & 0 & 0 & $1(4.5)$ & 22 & 9.7 \\
\hline Police or defence & $7(28)$ & $13(52)$ & $4(16)$ & $1(4)$ & 0 & 25 & 11.1 \\
\hline Government & $18(22.5)$ & $35(43.8)$ & 19 (23.8) & $7(8.8)$ & $1(1.3)$ & 80 & 35.4 \\
\hline Unemployed & $18(35.3)$ & 19 (37.3) & $12(23.5)$ & $2(3.9)$ & 0 & 51 & 22.6 \\
\hline Total & $93(41.2)$ & $84(37.20)$ & $36(15.9)$ & $11(4.9)$ & $2(0.9)$ & 226 & 100 \\
\hline \multicolumn{8}{|l|}{ Income } \\
\hline$<5.000$ AED & $18(58.1)$ & $9(29)$ & $3(9.7)$ & $1(3.2)$ & 0 & 31 & 17.4 \\
\hline 5.000-10.000 AED & $22(56.4)$ & $10(25.6)$ & $5(12.8)$ & $2(5.10$ & 0 & 39 & 21.9 \\
\hline 11.000-20.000 AED & $13(24.5)$ & $26(49.1)$ & $9(17)$ & $5(9.4)$ & 0 & 53 & 29.8 \\
\hline$>20.000$ AED & $13(23.6)$ & $25(45.5)$ & $12(21.8)$ & $3(5.5)$ & $2(3.60)$ & 55 & 30.9 \\
\hline Total & 66 (36.9) & 70 (39.7) & $29(16.2)$ & $11(6.1)$ & $2(1.10)$ & 178 & 100 \\
\hline \multicolumn{8}{|l|}{ Car type } \\
\hline Saloon & $42(41.2)$ & $42(41.2)$ & $11(10.8)$ & $5(4.9)$ & $2(2)$ & 102 & 50 \\
\hline Four-wheel & 38 (39.6) & $31(32.3)$ & $21(21.9)$ & $6(6.3)$ & 0 & 96 & 47.1 \\
\hline Truck & 0 & $1(100)$ & 0 & 0 & 0 & 1 & 0.5 \\
\hline Other & $3(60)$ & $1(20)$ & $1(20)$ & 0 & 0 & 5 & 2.5 \\
\hline Total & $83(40.7)$ & $75(36.8)$ & $33(16.2)$ & $11(5.4)$ & $2(1)$ & 204 & 100 \\
\hline \multicolumn{8}{|l|}{ RTC History } \\
\hline Yes & $32(36.8)$ & $30(34.5)$ & 17 (19.5) & $7(8)$ & $1(1.1)$ & 87 & 39.7 \\
\hline No & $62(47)$ & $49(37.1)$ & $16(12.1)$ & $4(3)$ & $1(0.8)$ & 132 & 60.3 \\
\hline Total & $94(42.9)$ & 79 (36.1) & $33(15.1)$ & $11(5.0)$ & $2(0.1)$ & 219 & 100 \\
\hline \multicolumn{8}{|l|}{ Wear seat belt } \\
\hline Yes & $13(31.7)$ & $13(31.7)$ & $8(19.5)$ & $6(14.6)$ & $1(2.4)$ & 41 & 47.1 \\
\hline No & $23(50)$ & $14(30.4)$ & $8(17.4)$ & $1(2.2)$ & 0 & 46 & 52.9 \\
\hline
\end{tabular}


Table 1 Demographic characteristics of the study respondents (Continued)

\begin{tabular}{|c|c|c|c|c|c|c|c|}
\hline & \multicolumn{6}{|c|}{ Age groups } & \multirow{2}{*}{$\begin{array}{l}\text { Percentage } \\
\text { within } \\
\text { nationality }\end{array}$} \\
\hline & $<=25$ & $26-35$ & $36-45$ & $46-55$ & $>55$ & Total & \\
\hline Total & $36(41.4)$ & $27(31)$ & $16(18.4)$ & $7(8)$ & $1(1.1)$ & 87 & 100 \\
\hline \multicolumn{8}{|c|}{ RTC as Driver } \\
\hline No & $80(44.1)$ & $64(35.4)$ & $29(16)$ & $6(3.3)$ & $2(1.1)$ & 181 & 78.4 \\
\hline Yes & $18(36)$ & $20(40)$ & $7(14)$ & $5(10)$ & 0 & 50 & 21.6 \\
\hline Total & $98(42.4)$ & $84(36.4)$ & $36(15.6)$ & $11(4.8)$ & $2(0.9)$ & 231 & 100 \\
\hline \multicolumn{8}{|c|}{ Significant RTC as Driver } \\
\hline No & $90(43.9)$ & $76(37.1)$ & $2(14.1)$ & $9(4.4)$ & $1(0.5)$ & 205 & 88.7 \\
\hline Yes & $8(30.8)$ & $8(30.8)$ & $7(26.9)$ & $2(7.7)$ & $1(3.8)$ & 26 & 11.3 \\
\hline Total & $98(42.4)$ & $84(36.4)$ & $36(15.6)$ & $11(4.8)$ & $2(0.9)$ & 231 & 100 \\
\hline
\end{tabular}

vehicle. On the other hand, driving when feeling sleepy was a risky behaviour that is considerably prevalent, with $47.3 \%$ reporting having done it. Aggressive violations, such as racing away from a traffic light with the intention of beating the driver next to them and sounding a horn to indicate annoyance to another road user, was reported by 18.6 and $23.3 \%$ of respondents, respectively.

Distracted behaviour was even more prevalent (Fig. 3). Responses to the Distracted Drivers Survey (DDS) shows that $55.7 \%$ of the respondents are distraction prone (distraction score less than 12) and $44.3 \%$ distraction averse (distraction score more than 11). One in five (19.4\%) have a distraction score of 20 or more (Table 2). The most distraction prone group is younger people $(90.5 \%$ are less than 36 years old). With regression analysis, a high DBQ score is associated with a high distraction score $(p<0.001)$. Age, on the other hand, is the other associated factor with the distraction score but it has an inverse relationship: the younger the responder, the higher the distraction score $(p=0.003)$. The most prevalent distractions were talking on the phone, reading messages, viewing maps, reading text messages, or eating or drinking, with a range from 23.2 to $35.2 \%$ never having engaged in these activities.
The main purpose of this study was to predict important associations between studied variables for risky drivers and these were identified using regression analysis. Higher scores from the DBQ were associated with higher PHQ-9 scores $(p<0.0001)$, more consideration of placing financial fines $(<0.0001)$, use of live recording social media when driving $(p=0.003)$, smoking while driving $(p=0.026)$, and reading WhatsApp while driving $(\mathrm{p}<0.0001)$.

Distracted drivers, as a risk factor for RTC, are more likely to be younger $(p<0.0001)$, eat out more frequently $(p=0.021)$, have violations related to speeding $(p=$ $0.001)$, have driven with no license $(p=0.008)$, or have driven in bad mood $(p=0.038)$. On the other hand, participants reporting a higher risk of depression are more likely to be older $(p=0.028)$, with a history of significant RTCs $(p<0.0001)$, with a higher GAD-7 score $(\mathrm{p}<$ 0.0001), and a higher Drivers Behaviour Questionnaire score $(\mathrm{p}<0.0001)$. Figure 4 shows these associations.

Self-reported RTC was significantly associated with high PHQ-9 scores $(p<0.001$ OR is $1.144(1.056-1.240)$, age, $p=0.023$ OR is $1.051(1.006-1.098))$ and a high distraction score $(p=0.018$ OR is $1.049(1.008-1.091))$. For each one-point increase in the PHQ-9 score, the risk of an RTC increased by $4.4 \%$. With each one-point increase

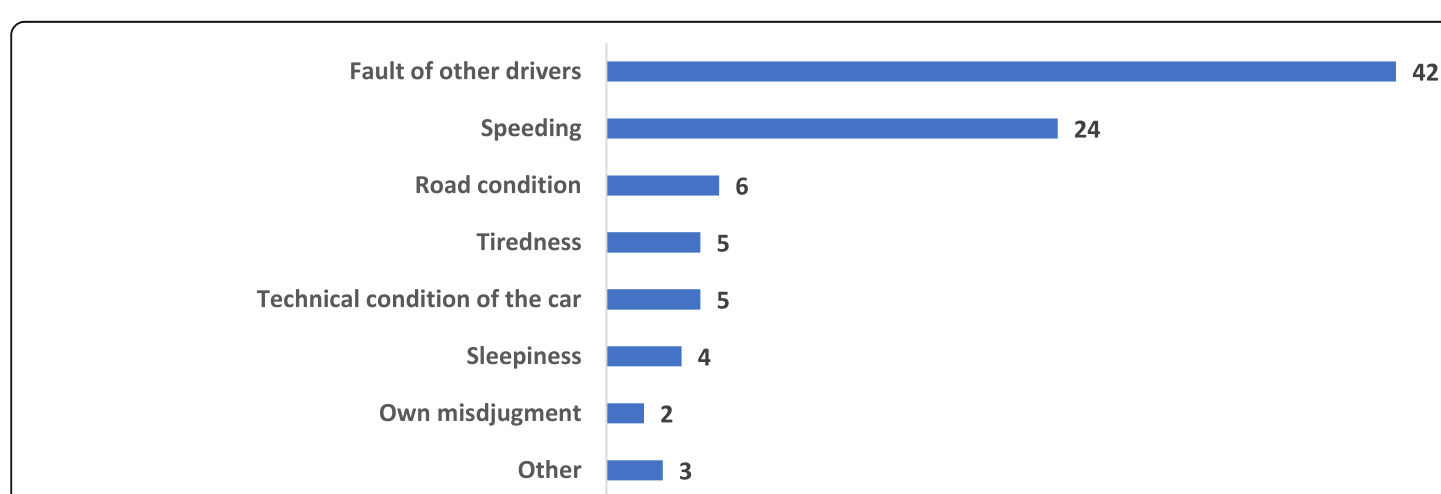

Fig. 1 Causes of the RTC reported in the respondent's opinion 


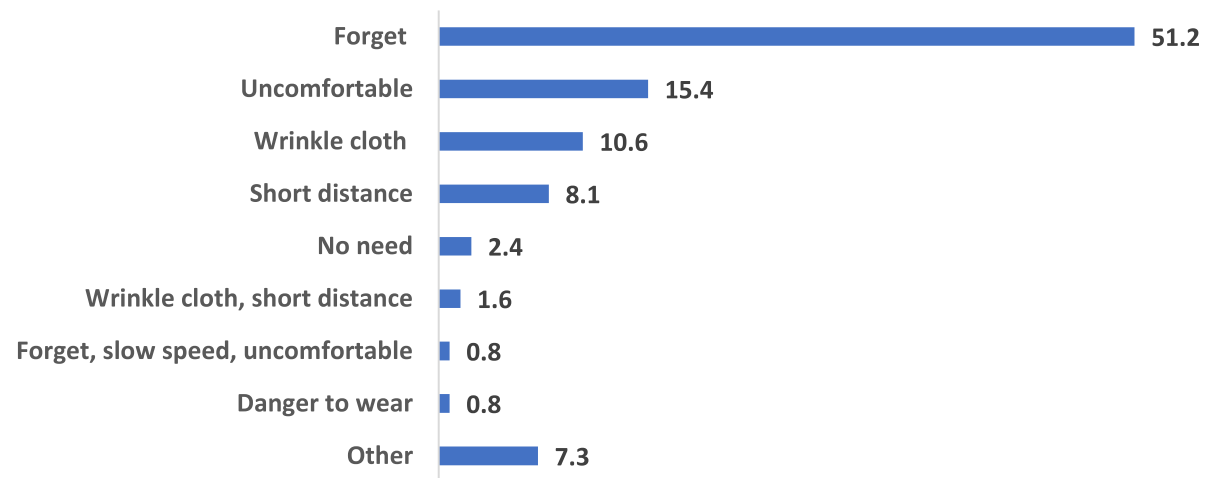

Fig. 2 Reasons mentioned by the respondents for not wearing the seatbelt while driving

in the distracted drivers' score (which is reported on a 0-44 scale with 44 being highest risk behaviours), the likelihood of reporting a car crash increased by $4.9 \%$, and with each additional year in age the RTC risk increased by $5.1 \%$. See Table 4 .

None of the other variables surveyed, including gender, occupation, income, education, nationality, BMI, physical activity, smoking, medical history of any chronic illness years since starting to drive and using seatbelt, showed any significant association with self-reported RTC.

\section{Discussion}

This study validated a tool to assess driving behaviour among adults in Abu Dhabi Emirate, United Arab

Table 2 Distribution of the four main survey parts. A. Drivers' Behaviour survey, B. Drivers' Distraction survey, C. PHQ-9 and D. GAD-7

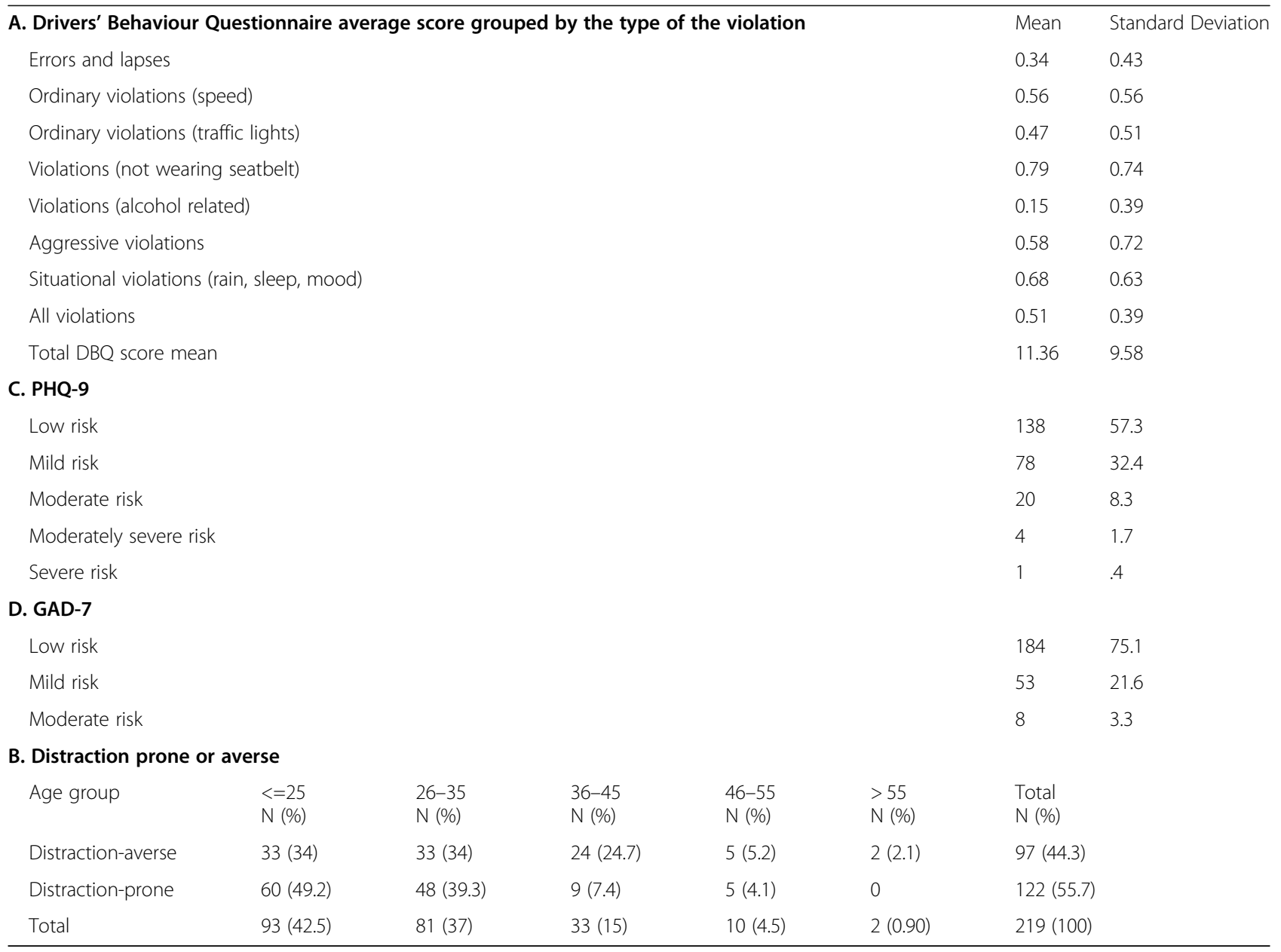


Table 3 Reponses to the Drivers' Behaviour Questionnaire's questions

\begin{tabular}{|c|c|c|c|c|c|c|}
\hline Questions & Mean & SD & Never (\%) & Sometimes (\%) & $\begin{array}{l}\text { Most of the } \\
\text { time (\%) }\end{array}$ & Always (\%) \\
\hline You drove after taking Alcohol & 0.87 & 0.87 & 88.5 & 9.5 & 1.4 & 0.7 \\
\hline You drove after taking an illicit drug such as marijuana or ecstasy & 0.87 & 0.91 & 87.9 & 10 & 1.7 & 0.3 \\
\hline You carried more passengers than could legally fit in your car & 0.79 & 0.82 & 85.7 & 12.3 & 1.4 & 0.7 \\
\hline Race away from traffic lights with the intention of beating the driver next to you & 0.71 & 0.83 & 81.4 & 16.9 & 1.3 & 0.4 \\
\hline Do you participate in drifting on the normal road & 0.66 & 0.79 & 79.3 & 17.3 & 2.4 & 1 \\
\hline Disregard the speed limit on a residential road/city/highway & 0.65 & 0.73 & 78.9 & 16.9 & 3.4 & 0.8 \\
\hline $\begin{array}{l}\text { You drove without a valid license because you hadn't applied for one yet or it } \\
\text { had been suspended }\end{array}$ & 0.65 & 0.68 & 78.3 & 18.3 & 2.4 & 1 \\
\hline Sound your horn to indicate your annoyance to another road user & 0.41 & 0.63 & 76.7 & 20 & 2.4 & 0.8 \\
\hline Hit something when reversing that you had not previously seen & 0.60 & 0.73 & 75.1 & 22.7 & 1.7 & 0.4 \\
\hline Queuing to turn left onto a main road, you nearly hit the car in front of you & 0.57 & 0.73 & 74.7 & 21.8 & 2.6 & 0.9 \\
\hline $\begin{array}{l}\text { Fail to notice that pedestrians are crossing when turning into a side street from } \\
\text { a main road }\end{array}$ & 0.58 & 0.72 & 73.7 & 24.6 & 0.8 & 0.8 \\
\hline You did illegal U-turn & 0.52 & 0.71 & 72.4 & 24.1 & 2.7 & 0.7 \\
\hline Get into the wrong lane approaching a roundabout or a junction & 0.47 & 0.68 & 71.9 & 24.3 & 3 & 0.9 \\
\hline Misread the signs and exit from a roundabout on the wrong road & 0.45 & 0.63 & 67.5 & 29.4 & 2.2 & 0.9 \\
\hline Does your over speed changed (stopped speeding) with any fine you paid & 0.43 & 0.71 & 67.1 & 24.3 & 6.5 & 2.1 \\
\hline You misjudged the speed of an oncoming vehicle & 0.36 & 0.57 & 61.5 & 32.3 & 5.5 & 0.7 \\
\hline You turned right into the path of another & 0.33 & 0.58 & 60.8 & 33.4 & 3.4 & 2.4 \\
\hline Forget where you left your car in a carpark & 0.32 & 0.56 & 59 & 32.1 & 7.3 & 1.7 \\
\hline You drove faster if you were in a bad mood & 0.30 & 0.56 & 56.2 & 32.9 & 9.2 & 1.7 \\
\hline $\begin{array}{l}\text { If there was no red light camera, you drove through intersections on a } \\
\text { red light }\end{array}$ & 0.29 & 0.52 & 53 & 38.2 & 6.4 & 2.4 \\
\hline You drove when you knew you were feeling sleepy & 0.27 & 0.51 & 52.7 & 36.1 & 9.5 & 1.7 \\
\hline Do you rush to catch an event & 0.25 & 0.55 & 50.2 & 37.1 & 9.3 & 3.4 \\
\hline You didn't wear a seatbelt if it was only for a short & 0.21 & 0.47 & 49.2 & 33.7 & 13.8 & 3.4 \\
\hline $\begin{array}{l}\text { You drove over the speed limit in areas where it was unlikely there was a radar } \\
\text { or speed camera }\end{array}$ & 0.26 & 0.56 & 47.1 & 44.1 & 5.8 & 3.1 \\
\hline You speed up when the lights went yellow & 0.26 & 0.55 & 45 & 47 & 6.4 & 1.7 \\
\hline Do you rush to be on time for work or school & 0.17 & 0.46 & 42 & 41.7 & 11.9 & 4.4 \\
\hline Your passengers didn't wear seatbelts & 0.14 & 0.42 & 41.3 & 38.6 & 12.4 & 7.7 \\
\hline You drove in the rain & 0.14 & 0.44 & 39.9 & 38.5 & 16.2 & 5.4 \\
\hline DBQ Average score & 0.27 & 0.55 & 54.03 & 35.89 & 7.76 & 2.36 \\
\hline
\end{tabular}

Emirates. The tool has proved to be useful to describe the current situation and to provide advice regarding important predictors of risk-taking while driving. The questions from the Manchester Driver Behaviour Questionnaire (DBQ) [13] and the Behaviour of Young Novice Drivers Scale (BYNDS) [14] were used in many countries, including the United Arab Emirates and Qatar [12, 18]. The cross-country comparisons of the DBQ concluded that the scores can be compared with a confidence [19]. Important additions are areas of growing interest: impact on drivers, mental health and driving distractions [20].

The participants surveyed in this study admitted fewer of the listed behaviours than did those from Britain,
Finland or the Netherlands [12]. Violations were more prevalent in Europe, while in Abu Dhabi non-use of seatbelts and other ordinary violation, such as speeding to catch an event or to get to work, were more common. Less prevalent behaviours among Abu Dhabi drivers were aggressive behaviour and driving under the influence of alcohol.

The prevalence of self-reported RTC (39.8\%) is high especially, that half of participants were the drivers. The opinion what caused the RTC shows an alarming picture, although it cannot be considered to be the true reflection of reality. It was rare for the respondents to identify the fault in the RTC to be the reporting driver. 


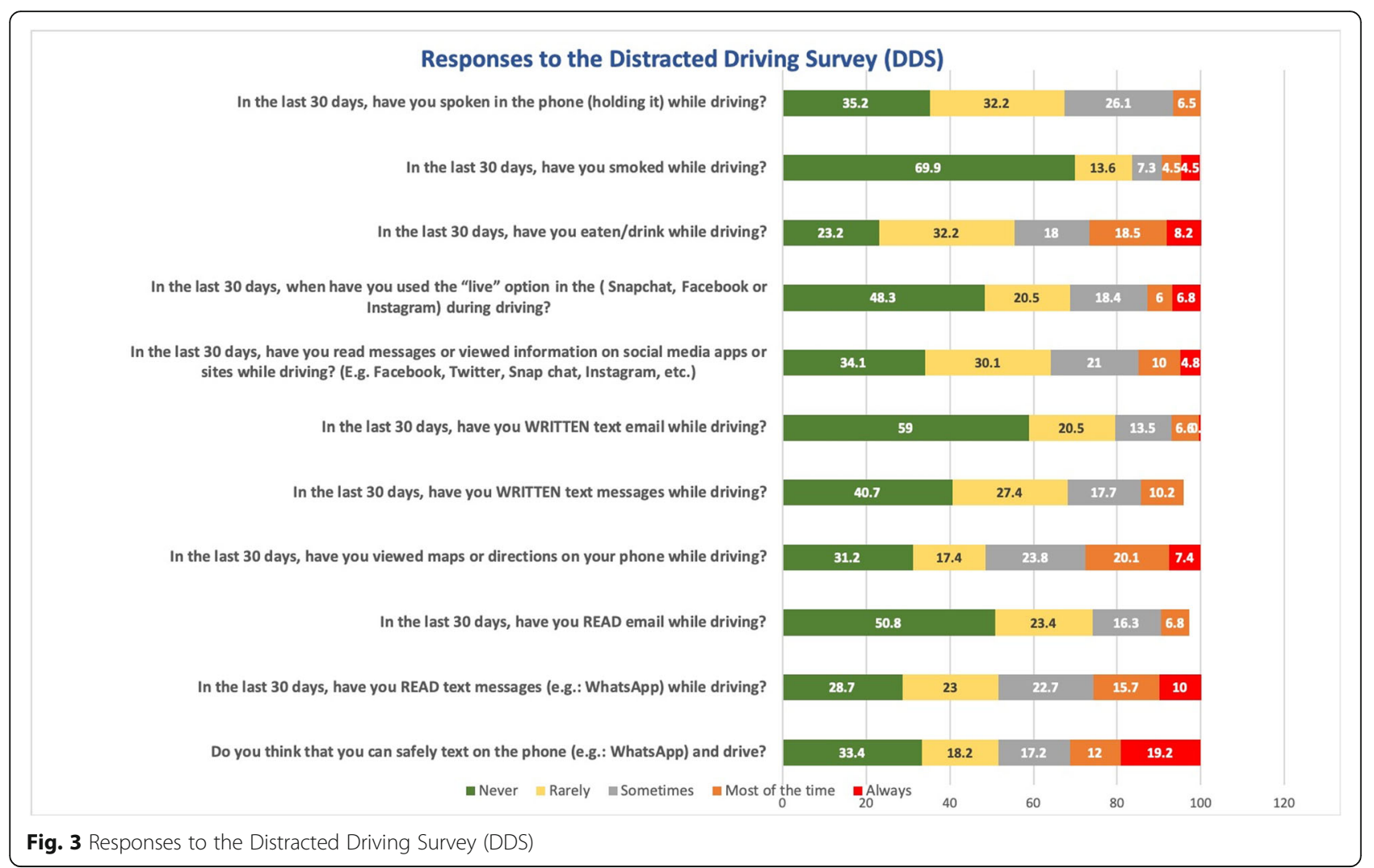

The tool also identified risky choices taken by the study participants while driving. Regarding the prediction of an RTC in this study, those reporting more violations related to aggressive behaviour, driving sleepy or under rainy conditions, driving in bad mood or having a high.

PHQ-9 score were more likely to report an RTC than those with no RTC history. The environmental factors and road designs are playing an important role in traffic safety $[21,22]$ The attention of the driver is important in order to see road defects or anomalies in the road design and appropriately react at the urban intersections $[21,22]$. Although years since the start of driving was not significant with having an RTC history, age was such a factor.

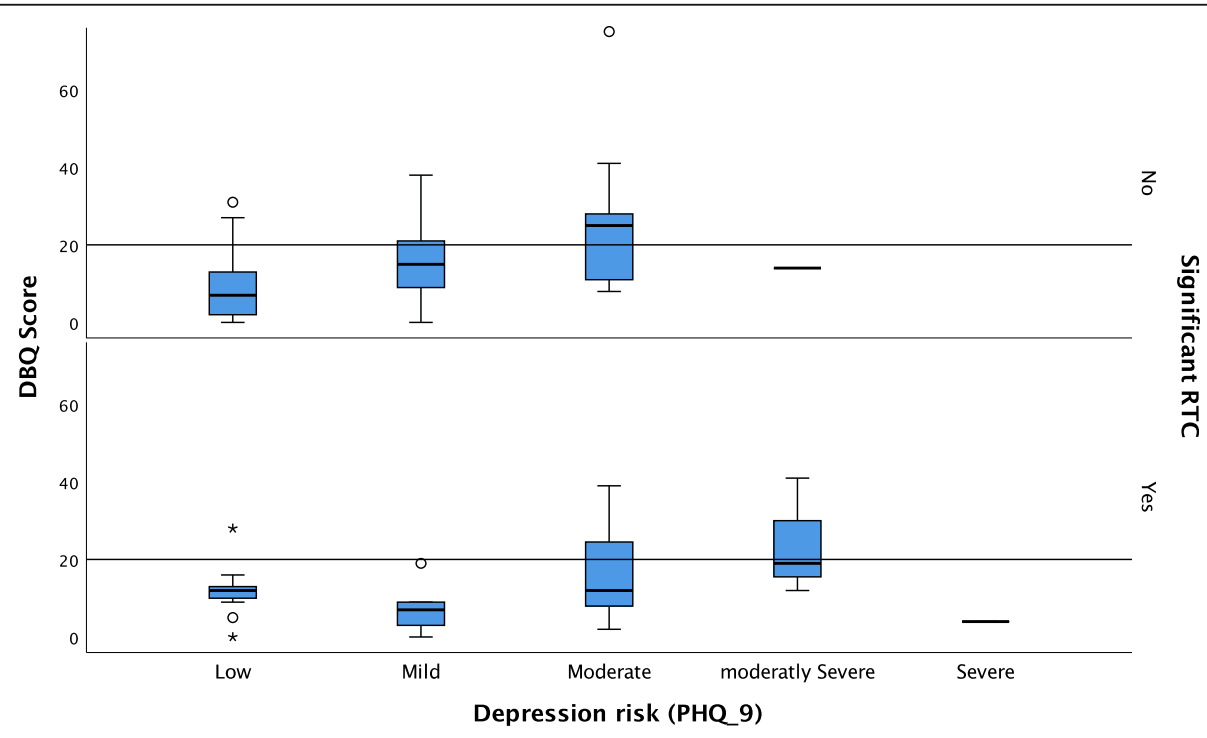

Fig. 4 Risk of depression (PHQ-9 score category) related to Drivers' Behaviour Questionnaire score and the history of significant RTC 
Table 4 Determinants of A. Drivers' Behaviour Questionnaire (DBQ), B. Distraction Score, C. Patient Health Questionnaire (PHQ-9) Score using regression

\begin{tabular}{|c|c|c|c|c|}
\hline & B & $P$-value & \multicolumn{2}{|c|}{$95.0 \% \mathrm{Cl}$} \\
\hline \multicolumn{5}{|l|}{ A. Driver Behaviour Questionnaire DBQ } \\
\hline PHQ 9 Score & 0.493 & 0 & 0.287 & 0.699 \\
\hline $\begin{array}{l}\text { Changes behaviour after financial } \\
\text { fines }\end{array}$ & 5.418 & 0 & 4.148 & 6.687 \\
\hline Using snap while driving & 1.38 & 0.003 & 0.47 & 2.289 \\
\hline Smoking while driving & 1.013 & 0.026 & 0.125 & 1.901 \\
\hline Reading WhatsApp while driving & 1.543 & 0 & 0.745 & 2.342 \\
\hline \multicolumn{5}{|l|}{ B. Distraction Score } \\
\hline Age & -0.21 & 0.021 & -0.38 & -0.03 \\
\hline Eating out frequently & 1.261 & 0.033 & 0.101 & 2.42 \\
\hline Violations Speeding & 4.827 & 0.001 & 1.955 & 7.699 \\
\hline Driving without license & 3.285 & 0.008 & 0.854 & 5.716 \\
\hline Driving in bad mood & 2.264 & 0.038 & 0.131 & 4.398 \\
\hline \multicolumn{5}{|l|}{ C. PHQ-9 } \\
\hline History of being the driver in a RTC & 1.09 & 0.028 & 0.119 & 2.06 \\
\hline Age & 0.047 & 0.057 & -0.001 & 0.096 \\
\hline $\begin{array}{l}\text { History of being the driver in a RTC } \\
\text { that results in Significant impact as } \\
\text { major injury or admission. }\end{array}$ & 2.987 & 0 & 1.672 & 4.302 \\
\hline GAD-7 Score & 0.715 & 0 & 0.591 & 0.838 \\
\hline DBQ Score & 0.115 & 0 & 0.074 & 0.157 \\
\hline
\end{tabular}

Significantly, experience with the RTC is greater among those reporting certain behaviours, such as traffic light violations or driving under the influence of alcohol. Most importantly, violations and lapses predicted selfreported RTCs. Although many studies found that DBQ was a prominent measurement scale to examine drivers' self-reported aberrant behaviours, some experts have argued against this conclusion and that using only selfreported data is not reliable [23, 24]. It is possible that underreporting is high due to recall bias. A recent study reached a similar conclusion, namely that methodological factors and dissemination bias have inflated the published effect sizes of the DBQ and that a greater level of care should be taken if the DBQ continues to be used in traffic safety research [25]. A study of registered RTCs, not self reported, in correlation to the tool used in this study, DBQ, is needed in the UAE to assess the tool as a correct predictor of RTC.

The low rate of seatbelt usage and reasons for not wearing a seatbelt suggest a possible lack of insights regarding potential fatal consequences. Being forgetful and feeling uncomfortable are the most common reasons given for not using a seatbelt, but one in ten stated that it is due to wrinkling their clothes. This necessitates appropriate measures to increase community awareness.
With 61\% reporting seatbelt usage always or most of the time in this study, this is a considerably lower figure compared to seatbelt use in the US, where $94 \%$ of drivers wear a seatbelt [26]. On the other hand, this score is higher than others reported in the region, such as in Saudi Arabia (34\%). Additionally, around half of those involved in an RTC in this study were not wearing a seatbelt at the time of the RTC [27]. A recent study in the US regarding seatbelt use by drivers involved in fatal RTCs reported that half of them were not wearing a seatbelt. Compared to belted drivers, unbelted drivers were over four times more likely to die in an RTC [26].

Regarding the drivers' mental health and its association with making risky choices, this consideration emerged as an area needing further research and interventions. With one out of ten of the respondents having a risk of mild to severe depression, this number is similar to reported prevalence in the UAE, between 12.5 and 28.6\% [28]. Also, those with high PHQ-9 scores reported having more significant RTCs and risky driving behaviours. These findings raise the question of whether mental status would be the cause or the result of the RTC. Evidence is growing that has examined rates of RTCs and traffic violations for drivers with mental illnesses, while other studies have examined the performance of people with mental illnesses on driving simulators [29]. Drivers who reported feeling depressed were more than twice as likely to be at fault for their collision than drivers who did not report such feelings. Additionally, depression was associated with increased aggressive and risky driving behaviour. The epidemiological evidence is increasingly showing that depression may have a detrimental impact on collision risk [30]. In a study assessing 208 inpatient psychiatric patients in the areas of reaction time, anticipation of speed, coordination, decisionmaking skills, and risk-taking, only 33 had scores compatible with the requirements to obtain a driver's license, and $84 \%$ failed at least one of the required tests. Of patients with a driver's license who drive almost every day, $79.5 \%$ registered scores that would not allow them to obtain or renew their licenses [31]. In this study, risk of depression was a determinant factor that requires future research and consideration by traffic safety authorities.

Finally, it was alarming to find the high distraction scores in this sample. Bergmark et al. [17] found that texting "always" while driving was a response of $7 \%$ in their study, compared to $19.2 \%$ in this sample. Viewing maps while driving was $4.8 \%$ in their study, compared to $7.4 \%$ in this study. Those who always read text messages while driving were $2.2 \%$ in their study, compared to $10 \%$ in this study. All indicating higher rates among respondents of this study. Finally, those who read messages or viewed information on social media apps or sites while driving was $2.2 \%$ in their study, compared to double the 
rate in this study, $4.8 \%$. All of these factors, in addition to highly prevalent distractions such as talking on the phone or eating or drinking while driving, reflect a risky behaviour that necessitates immediate and firm multifaced interventions.

In a recent study in Saudi Arabia using a mobile phone was associated with higher severity and prevalence of disability rates and was associated with a $44 \%$ greater likelihood of incurring a severe RTC [32]. Worldwide figures on the impact of distraction while driving to RTC ranges from $8 \%$ in the Netherlands, $11 \%$ in the US, to $37 \%$ in Spain [33]. Compared to the study by Bergmark et al. [17], which is similar to this study, a significant association was found between DDS and an RTC history. In their study, for every single unit increase of the DDS score, the likelihood of reporting a car crash increases by $7 \%$, compared to $4.9 \%$ in this study.

There are couple of limitations in our study. The results were based on the convenient sample so it is difficult to draw conclusions that can be generalized to the whole UAE population. Nevertheless, it highlights the risky driving behaviour, especially among young drivers in the UAE using validated tools. Although selfreporting of behaviour has been mentioned as having a risk of recall and reporting bias, there is sufficient evidence from the literature on the DBQ if there is similar risk of bias $[23,24]$ and in reporting about other behaviours, such as seatbelt usage, that self-reporting of behaviour represents an efficient alternative to observational studies for tracking changes in actual behaviour [34].

\section{Conclusions}

Drivers' behaviour in the UAE is risky, drivers are highly distracted, and depression must be considered as an important factor in risky driving. While there have been numerous technological advancements in vehicular and environmental safety, human behaviours, as distracted driving or not-use of restraints frequently contribute to severe injuries and fatalities in RTCs. Younger people were more likely to be distracted, while Depression is suggested as a determinant factor in risky driving. The concluded risk factors for RTC, including distractibility and risky behaviour may not be only specific to the study social and environmental conditions in the UAE. The study's results may be applied in other countries, especially that UAE have large number of nationalities and there was no difference found in determinants of behaviour between UAE and non-UAE populations. Nevertheless, this is to be confirmed by replicating the study elsewhere.

\section{Abbreviations}

UAE: United Arab Emirates; GDP: Gross Domestic Product; RTC: Road Traffic CollisionDBQManchester Driver Behaviour Questionnaire; BYNDS: Behaviour of Young Novice Drivers Scale; PHQ9: Patient Health Questionnaire; GAD7: Generalised Anxiety Disorder; AED: UAE Dirham (currency)

\section{Acknowledgements}

We would like to acknowledge Mrs. Amna Al Saadi and Mrs. Hanan Abdel Baqi for data collection coordination and follow up.

\section{Authors' contributions}

LBK have conceptualised conducted analysed the data and written the manuscript. MG have participated in conceptualising of the study and reviewed the manuscript. SA assisted in conceptualising and reviewing the manuscript. All authors reviewed and approved a final version of the manuscript.

\section{Funding}

This research did not receive any specific grant from funding agencies in the public, commercial, or not-for-profit sectors.

\section{Availability of data and materials}

The datasets used and/or analysed during the current study available from the corresponding author on reasonable request.

\section{Ethics approval and consent to participate}

Ethical approval for this study was obtained from AHS Human Ethics Committee. Participation was voluntary and all questions were anonymous. All participants signed consent for participation.

\section{Consent for publication}

Not Applicable.

\section{Competing interests}

None.

\section{Author details}

${ }^{1}$ Ambulatory Healthcare Services. Abu Dhabi Healthcare Services, $81815 \mathrm{Al}$ Ain, United Arab Emirates. ${ }^{2}$ Institute of Public Health, College of Medicine and Health Sciences, United Arab Emirates University, Al Ain, United Arab Emirates. ${ }^{3}$ College of Public Health, Abu Dhabi University, Abu Dhabi, United Arab Emirates.

Received: 9 April 2020 Accepted: 16 August 2020

Published online: 31 August 2020

References

1. Bank W. World Bank. 2017. The High Toll of Traffic Injuries: Unacceptable and Preventable. 2017

2. U.S. Department of Transportation NHTSA. The Economic and Societal Impact Of Motor Vehicle Crashes, 2010 (Revised). 2015.

3. (IIHS) TIIFHS. 2017

4. El-Sadig M, Norman JN, Lloyd OL, Romilly P, Bener A. Road traffic accidents in the United Arab Emirates: trends of morbidity and mortality during 1977 1998. Accid Anal Prev. 2002;34:465-76.

5. Data H. The Institute for Health Metrics and Evaluation (IHME). 2017. http:// www.healthdata.org/united-arab-emirates.

6. PopulationPyramid. UAE Population Pyramid. 2019

7. Valen A, Bogstrand ST, Vindenes V, et al. Driver-related risk factors of fatal road traffic crashes associated with alcohol or drug impairment. Accid Anal Prev. 2019;131:191-9.

8. Grivna M, Eid HO, Abu-Zidan FM. Pediatric and youth traffic-collision injuries in Al Ain, United Arab Emirates: a prospective study. PLoS One. 2013;8: e68636.

9. Herman J, Ameratunga S, Jackson R. Burden of road traffic injuries and related risk factors in low and middle-income Pacific Island countries and territories: a systematic review of the scientific literature (TRIP 5). BMC Public Health. 2012;12:479.

10. Mansuri FA, Al-Zalabani AH, Zalat MM, Qabshawi RI. Road safety and road traffic accidents in Saudi Arabia. A systematic review of existing evidence. Saudi Med J. 2015:36:418-24.

11. Bonnet $E$, Lechat $L$, Ridde $V$. What interventions are required to reduce road traffic injuries in Africa? A scoping review of the literature. PLoS One. 2018; 13:e0208195. 
12. Lajunen T, Parker D, Summala H. The Manchester driver behaviour questionnaire: a cross-cultural study. Accid Anal Prev. 2004;36:231-8.

13. Lucidi F, Giannini AM, Sgalla R, Mallia L, Devoto A, Reichmann S. Young novice driver subtypes: relationship to driving violations, errors and lapses. Accid Anal Prev. 2010;42:1689-96.

14. Scott-Parker B, Watson B, King MJ, Hyde MK. Confirmatory factor analysis of the behaviour of young novice drivers scale (BYNDS). Accid Anal Prev. 2012; 49:385-91.

15. Alghnam S, Towhari J, Alkelya M, Binahmad A, Bell TM. The effectiveness of introducing detection cameras on compliance with mobile phone and seatbelt laws: a before-after study among drivers in Riyadh, Saudi Arabia. Inj Epidemiol. 2018;5:31.

16. Williams AF. Graduated driver licensing (GDL) in the United States in 2016: a literature review and commentary. J Saf Res. 2017;63:29-41.

17. Bergmark RW, Gliklich E, Guo R, Gliklich RE. Texting while driving: the development and validation of the distracted driving survey and risk score among young adults. Inj Epidemiol. 2016;3:7.

18. Bener A, Ozkan T, Lajunen T. The driver behaviour questionnaire in Arab gulf countries: Qatar and United Arab Emirates. Accid Anal Prev. 2008:40: $1411-7$.

19. Reason J, Manstead A, Stradling S, Baxter J, Campbell K. Errors and violations on the roads: a real distinction. Ergonomics. 1990;33:1315-32

20. Environment EUNDARFIAVSA. Driver distraction and inattention. SEVENTH FRAMEWORK PROGRAMME. 2012;FP7-SST-2012.4.1-3 GA No. 314050

21. Demasi F, Loprencipe G, Moretti L. Road safety analysis of urban roads: case study of an Italian municipality. Safety. 2018;4:58

22. Alfonsi R, Persia L, Antonino T, Usami DS. Advancements in road safety management analysis. Transport Res Procedia. 2016;14:2064-73.

23. de Winter JC, Dodou D. The driver behaviour questionnaire as a predictor of accidents: a meta-analysis. J Saf Res. 2010;41:463-70.

24. de Winter JC, Dodou D, Stanton NA. A quarter of a century of the DBQ: some supplementary notes on its validity with regard to accidents. Ergonomics. 2015;58:1745-69.

25. Af Wåhlberg AE, Barraclough P, Freeman J. The driver behaviour questionnaire as accident predictor; a methodological re-meta-analysis. J Saf Res. 2015;55:185-212.

26. Liu C, Huang Y, Pressley JC. Restraint use and risky driving behaviors across drug types and drug and alcohol combinations for drivers involved in a fatal motor vehicle collision on U.S. roadways. Inj Epidemiol. 2016;3:9.

27. Alghnam S, Alrowaily M, Alkelya M, Alsaif A, Almoaiqel F, Aldegheishem A. The prevalence of seatbelt and mobile phone use among drivers in Riyadh, Saudi Arabia: an observational study. J Saf Res. 2018;66:33-7.

28. Razzak HA, Harbi A, Ahli S. Depression: prevalence and associated risk factors in the United Arab Emirates. Oman Med J. 2019;34:274.

29. Wickens CM, Smart RG, Mann RE. The impact of depression on driver performance. Int J Ment Heal Addict. 2014;12:524-37.

30. Christine M, Wickens RGS, Robert E. Mann. The impact of depression on driver performance. Int J Ment Health Addiction. 2014;12:524-37.

31. De Las CC, Sanz EJ. Fitness to drive of psychiatric patients. Prim Care Companion J Clin Psychiatry. 2008;10:384-90.

32. Alghnam S, Towhari J, Alkelya M, et al. The association between Mobile phone use and severe traffic injuries: a case-control study from Saudi Arabia. Int J Environ Res Public Health. 2019;16:2706.

33. WHO. Mobile phone use: a growing problem of driver distraction. Geneva: World Health Organization; 2011.

34. Zambon F, Fedeli U, Marchesan M, Schievano E, Ferro A, Spolaore P. Seat belt use among rear passengers: validity of self-reported versus observational measures. BMC Public Health. 2008;8:233.

\section{Publisher's Note}

Springer Nature remains neutral with regard to jurisdictional claims in published maps and institutional affiliations.

Ready to submit your research? Choose BMC and benefit from:

- fast, convenient online submission

- thorough peer review by experienced researchers in your field

- rapid publication on acceptance

- support for research data, including large and complex data types

- gold Open Access which fosters wider collaboration and increased citations

- maximum visibility for your research: over $100 \mathrm{M}$ website views per year

At BMC, research is always in progress.

Learn more biomedcentral.com/submissions 